\title{
Increased expression of selected very late antigen integrin subunits on CD4 and CD8 blood T lymphocytes in patients with clinically stable asymptomatic atopic asthma
}

\author{
Stanisława Bazan-Socha, Joanna Żuk, Jacek Musiał \\ $2^{\text {nd }}$ Department of Internal Medicine, Unit of Allergy and Clinical Immunology, Jagiellonian University, Medical College, Krakow, Poland \\ Head: Prof. Jacek Musiał MD, PhD
}

Postep Derm Alergol 2012; XXIX, 5: 337-342 DOI: $10.5114 /$ pdia.2012.31485

\begin{abstract}
Introduction: Recruitment of the inflammatory cells from blood to the airways in asthma is mediated by adhesive molecules, e.g. selectins and integrins. The most important integrins in cells trafficking are molecules containing $\alpha_{4}$ and $\beta_{2}$ subunits. We hypothesized that also $\alpha_{1} \beta_{1}$ and $\alpha_{2} \beta_{1}$ integrins (both found by us on blood eosinophils of asthmatic subjects) are important in asthma pathogenesis.

Aim: To assess the expression of selected very late antigen (VLA) subunits $\left(\alpha_{1}, \alpha_{2}, \alpha_{4}\right.$ and $\left.\beta_{1}\right)$ on blood CD4 and CD8 T lymphocytes from stable atopic asthmatic patients.

Material and methods: The study was conducted on 25 adult atopic asthmatics (mild to moderate persistent asthma in a stable clinical condition) and 17 matched healthy controls using flow cytometry.

Results: Expression of $\alpha_{4}$ and $\beta_{1}$ on CD4 T cells was significantly higher in asthma than in controls. The $\alpha_{1}$ subunit was absent from blood lymphocytes. The $\alpha_{2}$ chain hardly detected on lymphocytes from healthy subjects was distinctively present in asthmatics. Surprisingly, in subjects suffering from asthma for longer than 4 years $(n=15)$, the overexpression of $\alpha_{2}, \alpha_{4}$ and $\beta_{1}$ was observed on both: CD4 and CD8 T cells.

Conclusions: Expression of selected VLA subunits on blood T cells may depend on asthma duration. The biological role of $\alpha_{2} \beta_{1}$ integrin in asthma is unknown, but as it was described as a stimulator of collagen accumulation in the airways, $\alpha_{2} \beta_{1}$ integrin could be, at least in part, responsible for asthma airway remodelling.
\end{abstract}

Key words: asthma, integrins, collagen receptors, airway remodelling, inflammation.

\section{Introduction}

Bronchial asthma is a chronic, inflammatory disease of the airways, which due to its frequency, poses an important public health problem. It is characterized by reversible airflow limitation and bronchial hyper-responsiveness; both leading to the distinct clinical symptoms: chest tightness, cough and breathlessness. Unfortunately, pathogenesis of asthma is only partially understood. It is associated with environmental factors together with variable inflammatory cell activation. T helper lymphocytes, in particular Th2 subtype are likely to be pivotal in directing the disease development and progression and leading to the eosinophilic airway inflammation. Activated Th2 cells are present in the airways even when the disease is quiescent. Adoptive transfer of Ag-primed T cells in naïve ani- mals induces eosinophilia, bronchial hyper-responsiveness and late airway response [1]. Eosinophils are considered the major effector cells in asthmatic airway inflammation. Interestingly, anti-IL-5 antibodies, able to reduce blood and lung eosinophilia, did not change asthma severity [2]. Some believe that non-eosinophilic inflammation and airway remodelling contribute to the persistence and progression of the disease, despite anti-inflammatory therapy [3].

Recruitment of the engaged cells is crucial to the development of the inflammatory reaction. This process is mediated by adhesive molecules, such as glycoproteins, selectins and integrins [4]. Integrins are a family of heterodimeric glycoproteins composed of non-covalently associated $\alpha$ and $\beta$ subunits. They are present on almost all viable cells and regulate between cell and cell to matrix interactions [5]. Also leukocyte migration into

Address for correspondence: Stanisława Bazan-Socha MD, 2 ${ }^{\text {nd }}$ Department of Internal Medicine, Unit of Allergy and Clinical Immunology, Jagiellonian University, Medical College, 8 Skawińska St, 31-066 Krakow, Poland, phone: +48 600294141, fax: +48 12 430 52 03, e-mail: mmsocha@cyf-kr.edu.pl 
the lung is mediated by integrins, in particular those containing $\alpha_{4}\left(\alpha_{4} \beta_{1}\right.$ and $\left.\alpha_{4} \beta_{7}\right)$ and $\beta_{2}$ subunits (LFA- 1 - integrin $\alpha_{L} \beta_{2}$ - CD11a/CD18; Mac-1 - integrin $\alpha_{M} \beta_{2}-$ CD11b/CD18, integrin $\alpha_{\times} \beta_{2}-$ CD11c/CD18 and integrin $\left.\alpha_{D} \beta_{2}-C D 11 d / C D 18\right)$. All those integrins have been intensively studied in inflammatory diseases, like asthma, and considered a possible therapeutic target $[6,7]$. We have previously suggested that collagen integrin receptors: $\alpha_{1} \beta_{1}$ and $\alpha_{2} \beta_{1}$, both found on peripheral blood eosinophils of asthmatic subjects, may be involved in asthma pathogenesis [8]. The $\alpha_{1} \beta_{1}$ integrin belongs to the $\beta_{1}$ integrin family (also called very late antigen-1 - VLA-1). It is a specific receptor for collagen IV, the main component of the small vessel basement membrane [9]. Very late antigen-1 is expressed inter alia on fibroblasts, mesenchymal and epithelial cells, macrophages and, NK and T lymphocytes after their activation [10]. It plays a role in angiogenesis, metastasis, cell migration and cytokine secretion. Anti-inflammatory effects of the VLA-1 antagonists were observed in animal models of arthritis [11], colitis [12], allergen-induced bronchoconstriction [13] and glomerulonephritis [14].

The $\alpha_{2} \beta_{1}$ integrin (VLA-2) is a collagen I receptor. Its main function is connected with haemostasis. VLA-2 also promotes neoplasm invasion [15]. But collagen I is also an important component of extracellular matrix of the lungs and VLA-2 was described as a stimulator of collagen and fibronectin accumulation in the airways - crucial element of airway remodelling [16, 17].

\section{Aim}

The aim of this study was to analyse the expression of collagen receptors: integrins $\alpha_{1} \beta_{1}$ and $\alpha_{2} \beta_{1}$ on peripheral blood CD4 and CD8 T lymphocytes in subjects with chronic clinically stable atopic asthma.

\section{Material and methods}

The study was conducted on 25 adult atopic asthmatics and 17 healthy controls. All asthma patients were in a stable clinical condition with mild $(n=15)$ to moder- ate $(n=10)$ persistent asthma, according to the GINA guidelines [18]. Their atopic status was confirmed by a positive skin testing for at least one standard inhaled allergen (Allergopharma, Germany). Most of them had a good or partially controlled asthma (GINA 2006) and were treated with a medium dose of inhaled glucocorticosteroids and long-acting $\beta_{2}$-agonists. Smokers and patients suffering from heart failure, diabetes mellitus, renal or hepatic diseases, as well as other chronic diseases were excluded from the study. The control group consisted of non-atopic and non-smoking volunteers, without any chronic illness. Our study was approved by the JagielIonian University Ethical Committee and all subjects gave informed consent to participate in this study.

Expression of $\alpha_{1}, \alpha_{2}, \alpha_{4}$ and $\beta_{1}$ integrin subunits on CD4 and CD8 peripheral blood T lymphocytes was analysed by flow cytometry (Epics XL, Beckman Coulter International, Nyon, Switzerland) and expressed as Median Fluorescence Intensity (MFI).

A $100 \mu \mathrm{l}$ samples of venous peripheral blood taken on EDTA was incubated with monoclonal antibodies (mAbs) in a concentration of $10 \mu \mathrm{l} / 100 \mu \mathrm{l}$ using threefold staining: 1) PerCP-conjugated mouse anti human-CD3 mAb for lymphocyte T detection;

2) FITC-conjugated mouse anti human-CD4 or CD8 mAb; 3) PE-conjugated mouse anti human - CD49a (anti- $\left.\alpha_{1}\right)$, or CD49b (anti- $\left.\alpha_{2}\right)$, or CD49d (anti- $\left.\alpha_{4}\right)$, or CD29 (anti- $\left.\beta_{1}\right)$ mAbs.

All monoclonal antibodies were purchased from BD Pharmingen, (San Diego, CA, USA). The isotypic control was performed using mouse IgG antibody against keyhole limpet hemocyanin antigen (KLH), purchased from Becton Dickinson Biosciences (San Jose, CA, USA) and PE, FITC

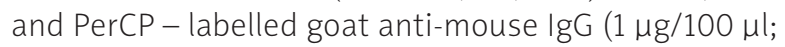
Jackson Immuno Research Laboratories, West Grove, PA, USA). Serum concentration of IgE and eosinophil cationic protein (ECP) was measured using UniCAP System, Pharmacia, Sweden.

\section{Statistical analysis}

Normally distributed results were reported in tables as a mean \pm standard deviation (SD). Values, which were

Table 1. Clinical and laboratory characteristics of the subjects studied

\begin{tabular}{|c|c|c|c|}
\hline Variable & Asthmatics $(n=25)$ & Healthy controls $(n=17)$ & Difference \\
\hline Male/female ratio & $9 / 16$ & $6 / 11$ & NS \\
\hline Age, mean \pm SD [years] & $42 \pm 14.5$ & $33 \pm 12$ & NS \\
\hline Duration of asthma, mean (min-max) [years] & $11(1-35)$ & & \\
\hline $\mathrm{FEV}_{1} \pm \mathrm{SD}(\%$ of predicted $)$ & $88 \pm 18$ & & \\
\hline Blood eosinophilia, median (interquartile range) $\left[/ \mathrm{mm}^{3}\right]$ & $177(134)$ & $82.8(57.5)$ & $p<0.05$ \\
\hline Total IgE, median (interquartile range) [IU/I] & $157(216)$ & $17.2(33)$ & $p<0.05$ \\
\hline Serum ECP, median (interquartile range) [UG/l] & $18(10.1)$ & $7.5(4)$ & $p<0.05$ \\
\hline
\end{tabular}


Table 2. Median Fluorescence Intensity (MFI) of analysed integrin subunits in all subjects studied (results shown as a median and interquartile range)

\begin{tabular}{lcccccc}
\hline $\begin{array}{l}\text { Subunits } \\
\text { analyzed }\end{array}$ & $\begin{array}{c}\text { Asthma } \\
\text { CD4 T cells }\end{array}$ & $\begin{array}{c}\text { Control } \\
\text { CD4 T cells }\end{array}$ & Difference & $\begin{array}{c}\text { Asthma } \\
\text { CD8 T cells }\end{array}$ & $\begin{array}{c}\text { Control } \\
\text { CD8 T cells }\end{array}$ & $\begin{array}{c}\text { Difference } \\
\alpha_{1}\end{array}$ \\
\hline$\alpha_{2}$ & $1.98(0.31)$ & $1.92(0.8)$ & NS & $2.07(0.26)$ & $2.05(0.41)$ & NS \\
\hline$\alpha_{4}$ & $4.24(2.18)$ & $3.56(1.05)$ & NS & $3.44(2.1)$ & $2.69(1.65)$ & NS \\
\hline$\beta_{1}$ & $10.5(4.54)$ & $8.14(3.19)$ & 0.02 & $15.9(4.6)$ & $12.8(4.1)$ & NS \\
\hline
\end{tabular}
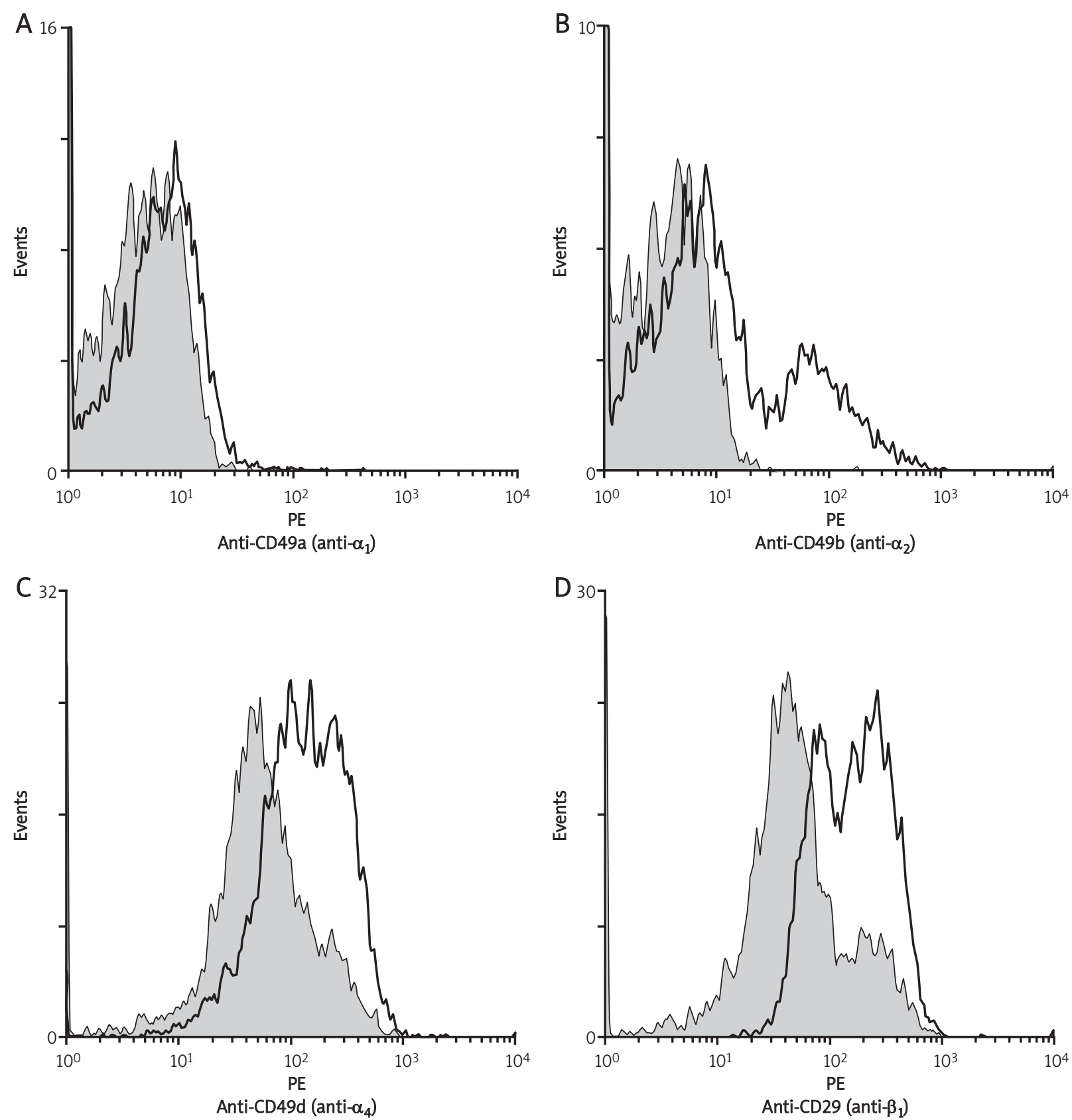

Figure 1. Example of the fluorescence pattern of studied integrin subunits in an asthma subject (bold line) and healthy control (thin line with shape shadow) 

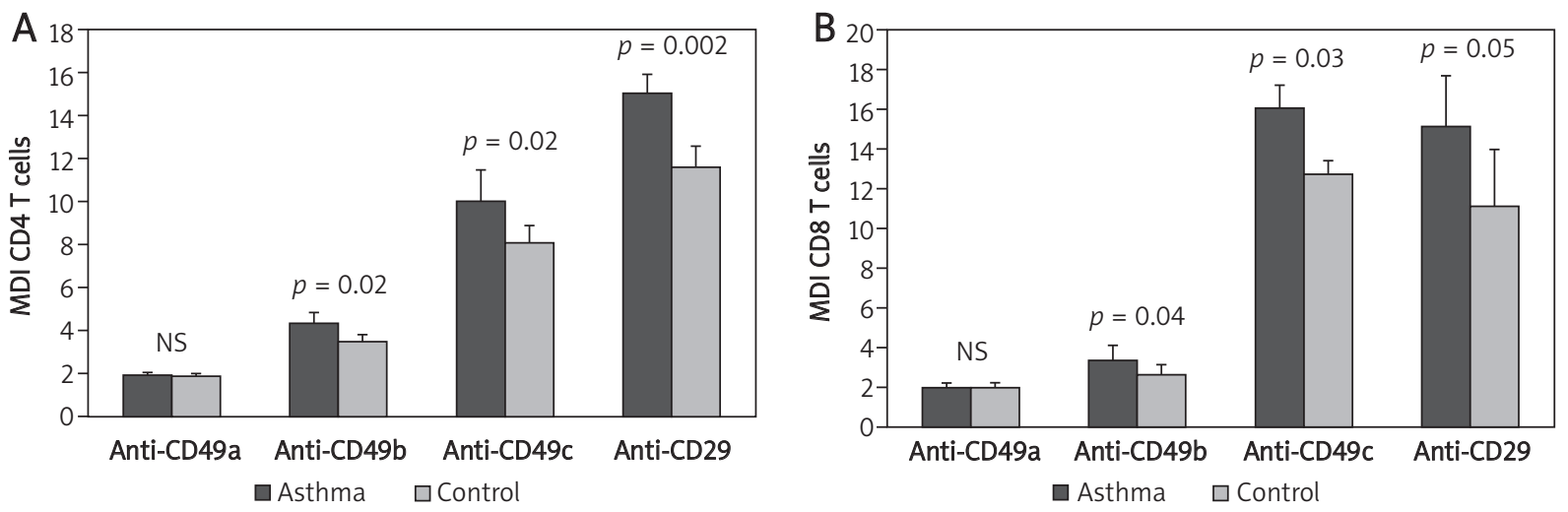

Figure 2. Median Fluorescence Intensity (MFI) of studied integrin subunits in a group of patients suffering from asthma for longer than 4 years $(n=15)$ in comparison to healthy controls $(n=17)$ (results shown as a median and standard error of median)

not normally distributed, were presented in tables as a median with interquartile range and in figures as a median with standard error of median. Comparison between experimental groups were tested using MannWhitney $U$ test, whilst relationships were tested using Spearman Rank Correlations. Two-sided 5\% level of significance was used. All statistical testing was performed by Statistica StatSoft (Tulsa, OK, USA) software.

\section{Results}

The summary of the results is shown in Tables 1, 2 and Figures 1 and 2. The groups studied were similar as to age and sex. Patients had significantly higher blood eosinophilia and serum levels of ECP and IgE (Table 1).

As shown in Table 2 and Figure 1, the expression of both $\alpha_{4}$ and $\beta_{1}$ chains was significantly higher in asthma subjects as compared to controls, but only for CD4 T cells ( $p=0.02$ and $p=0.0004$, respectively). The $\alpha_{1}$ subunit was absent in almost all subjects studied (only a few asthma patients had detectable fluorescence for $\alpha_{1}$ chain). On the other hand, $\alpha_{2}$ subunit was found on blood T lymphocytes of both studied groups, but its expression was low, slightly higher in asthma, particularly on CD4 T cells (the difference was not significant).

Surprisingly, in subjects suffering from asthma for longer than 4 years $(n=15)$ not only $\alpha_{4}$ and $\beta_{1}$, but also $\alpha_{2}$ chain was overexpressed on CD4 T cells, with $\alpha_{2}$ and $\alpha_{4}$ overexpression on CD8 (Figure 2).

Similarly, a significantly higher expression of $\alpha_{2}$, $\alpha_{4}$ and $\beta_{1}$ was observed on CD4 T cells in a group of patients with at least one asthma exacerbation during the last 12 months, in comparison to healthy subjects ( $n=9, p=0.04 ; p=0.04 ; p=0.001$, respectively).

No correlation was found between the chain expression, dose of inhaled steroids, IgE level, ECP or eosinophils count. A positive correlation was found for blood eosinophilia and ECP concentration $(p=0.009)$ only.

\section{Discussion}

An increased expression of $\alpha_{4}$ and $\beta_{1}$ subunits on blood CD4 T lymphocytes in clinically stable, asymptomatic asthmatics confirmed pre-activation and readiness for migration of these cells to the inflammatory site. However, in our studies, both chains were also detected on blood lymphocytes in healthy individuals and on peripheral blood eosinophils in healthy and asthmatic subjects [8]. Both are intensively studied as a possible therapeutic target in many inflammatory diseases, such as asthma $[6,7,19]$. Integrins containing $\alpha_{4}$ and $\beta_{1}$ subunits are important or even critical for immunity and body health control. For this reason blockade of $\alpha_{4}$ and $\beta_{1}$ could be hazardous and lead to unexpected outcomes. Natalizumab, a humanized $\operatorname{lgG}_{4}$ anti- $\alpha_{4}$-integrin monoclonal antibody inhibits both: $\alpha_{4} \beta_{7} /$ mucosal addressin-cell adhesion molecule-1 (MadCAM-1) and $\alpha_{4} \beta_{1}$ /vascular-cell adhesion molecule-1 (VCAM-1) interactions. Administration of natalizumab was shown to be highly effective in patients with multiple sclerosis and Crohn's disease [20, 21]. Unfortunately, it has been also implicated in some cases of progressive multifocal leukoencephalopathy, due to JC virus activation as a consequence of severe immunosuppression [22]. It seems that for therapeutic purposes, a target more selective and specific to a particular disease could be safer. In our study, an expression of $\alpha_{2}$ subunit on blood lymphocytes was low, but increased in patients suffering from asthma for longer than 4 years, even despite chronic anti-inflammatory therapy and lack of clinical symptoms. Our findings were not in a clear relationship with the type of treatment and current severity of symptoms. The biological function of $\alpha_{2} \beta_{1}$ in asthma is still unknown. An increased expression of this integrin was found by others on blood lymphocytes but only during severe exacerbation of asthma [23, 24]. We also found a higher expression of $\alpha_{2}$ subunit on CD4 T cells in patients, who had at least one exacerbation during the last year of the patient's observation. We speculate 
that integrin $\alpha_{2} \beta_{1}$ is not involved in lymphocyte transmigration but rather acts on turnover of the extracellular matrix, as a stimulator of remodelling. The $\alpha_{2} \beta_{1}$ integrin has been described previously as a stimulator of collagen and fibronectin accumulation in the airways [25]. Fibroblasts initiate collagen degradation through this integrin [26], whereas $\alpha_{1} \beta_{1}$ integrin is important in collagen fibrils organization and in feedback inhibition of collagen I synthesis [27]. Our findings indicate that an expression of $\alpha_{2}$ on $T$ cells is much lower than this observed for e.g. $\alpha_{4}$ and $\beta_{1}$. In our preliminary experiments with transmigration of eosinophil and lymphocyte through human extracellular matrix and collagen I coated inserts, blockade of $\alpha_{2}$ integrin subunit by functional active mAbs, as well as VP-12 (viper venom lectin - selective inhibitor of $\alpha_{2} \beta_{1}$ integrin) had no impact on lymphocyte transmigration, but decreased migration of eosinophils (data not published).

Till now airway remodelling could not be reversed. Current recommended asthma treatment is partially successful in limiting allergic inflammation but does not specifically address the remodelling process. Despite aggressive treatment asthma often progresses [28]. Clinical studies suggest that use of inhaled glucocorticoids before the age of 2 has no effect on asthma 8 years later [29]. Experimental asthma therapy with imatinib (tyrosine kinase inhibitor) can prevent airway inflammation and remodelling in the murine model by inhibition of collagen deposition [30,31]. The mode of such action is unknown, but could be connected to interaction with integrin collagen receptors. Integrin-linked cytoplasmic kinase can activate and regulate smooth muscle contraction directly by myosin phosphorylation and indirectly by myosin light-chain phosphatise inhibition [32]. There are only five known collagen integrin receptors: $\alpha_{1} \beta_{1}, \alpha_{2} \beta_{1}$, $\alpha_{3} \beta_{1}, \alpha_{10} \beta_{1}$ and $\alpha_{11} \beta_{1}$ [33]. We studied two of them, but it is tempting to speculate that integrin collagen receptors could become a new therapeutic target in treatment of asthmatic airway remodelling.

\section{Acknowledgments}

This work was supported by KBN - the State Committee for Scientific Research: registration number N N402 186835.

\section{References}

1. Cohn L, Elias JA, Chupp GL. Asthma: mechanisms of disease persistence and progression. Annu Rev Immunol 2004; 22: 789-815.

2. Leckie MJ, Brinke A, Khan J, et al. Effects of an interleukin-5 blocking monoclonal antibody on eosinophils, airway hyperresponsiveness, and late asthmatic response. Lancet 2000; 356: 2144-8

3. Gibson PG. What do non-eosinophilic asthma and airway remodelling tell us about persistent asthma? Thorax 2007; 62: 1034.
4. Hynes RO. Integrins: bidirectional, allosteric signaling machines. Cell 2002; 110: 673-87.

5. Fougerolles AR, Sprague AG, Nickerson-Nutter CL, et al. Regulation of inflammation by collagen-binding integrins alpha1beta1 and alpha2beta1 in models of hypersensitivity and arthritis. J Clin Invest 2000; 105: 721-9.

6. Banarjee ER, Jiang Y, Henderson WR, et al. Absence of alpha4 but not beta2 integrins restrains development of chronic allergic asthma using mouse genetic models. Exper Hematol 2009; 37: 715-27.

7. Gascoigne MH, Holland K, Page CP, et al. The effect of antiintegrin monoclonal antibodies on antigen-induced pulmonary inflammation in allergic rabbits. Pulm Pharmacol Ther 2003; 16: 279-85.

8. Bazan-Socha S, Bukiej A, Pulka G, et al. Increased expression of collage receptors: alpha1beta1 and alpha2beta1 integrins on blood eosinophils in bronchial asthma. Clin Exper Allergy 2006; 36: 1184-91.

9. Tawil NJ, Houde M, Blacher R, et al. alphalbetal integrin heterodimer functions as a dual laminin/collagen receptor in neural cells. Biochemistry 1990; 29: 6540-4.

10. Shomron BH, Ilan B. The role of very late antigen-1 in immune mediated inflammation. Clin Immunol 2004; 113: 119-29.

11. Ianaro A, Cicala C, Calignano A, et al. Anti-very late antigen-1 monoclonal antibody modulates the development of secondary lesion and T-cell response in experimental arthritis. Lab Invest 2000; 80: 73-80.

12. Krieglstein CF, Cerwinka WH, Sprague AG, et al. Collagen-binding integrin alpha1beta1 regulates intestinal inflammation in experimental colitis. J Clin Invest 2002; 110: 1773-82.

13. Abraham WM, Ahmed A, Serebriakov I, et al. A monoclonal antibody to alpha1beta1 blocks antigen-induced airway responses in sheep. Am J Respir Crit Care Med 2004; 169: 97-104.

14. Cook HT, Khan SB, Allen A, et al. Treatment with an antibody to VLA-1 integrin reduces glomerular and tubulointerstitial scarring in a rat model of crescentic glomerulonephritis. Am J Pathol 2002; 161: 1265-72.

15. Klein CE, Dressel D, Steinmayer T, et al. Integrin alpha2beta1 is upregulated in fibroblasts and highly aggressive melanoma cells in three-dimensional collagen lattices and mediates the reorganization of collagen I fibrils. J Cell Biol 1991; 115: 1427-36.

16. Fernandes DJ, Bonacci JV, Stewart AG. Extracellular matrix, integrins, and mesenchymal cell function in the airways. Curr Drug Targ 2006; 7: 567-77.

17. Karakis GP, Sin B, Tutkak H, et al. Genetic aspect of venom allergy: association with HLA class I and class II antigens. Ann Agric Environ Med 2010; 17: 119-23.

18. National Heart, Lung and Blood Institute. Global Strategy for Asthma Management and Prevention. National Institutes of Health, Bethesda, 1995 Global Initiative for Asthma, Publication No. 95 - 3659, NHLBI/WHO Workshop Report.

19. Hallas TE, Gislason T, Gislason D. Mite allergy and mite exposure in Iceland. Ann Agric Environ Med 2011; 18: 13-7.

20. Sotgiu S, Murrighile MR, Constantin G. Treatment of refractory epilepsy with natalizumab in a patient with multiple sclerosis. BMC Neurol 2010; 10: 84.

21. Guagnozzi D, Caprilli R. Natalizumab in the treatment of Crohn's disease. Biologics 2008; 2: 275-84.

22. Bartt RE. Multiple sclerosis, natalizumab therapy, and progressive multifocal leukoencephalopathy. Curr Opin Neurol 2006; 19: 341-9. 
23. Kasznia-Kocot J, Kowalska M, Górny RL, et al. Environmental risk factors for respiratory symptoms and childhood asthma. Ann Agric Environ Med 2010; 17: 221-9.

24. Corrigan CJ, Hartnell A, Kay AB. T lymphocyte activation in acute severe asthma. Lancet 1988; 1: 1129-32.

25. Fernandes DJ, Bonacci JV, Stewart AG. Extracellular matrix, integrins, and mensenchymal cell function in the airways. Curr Drug Targ 2006; 7: 567-77.

26. Lee H, Overall CM, McCulloch CA, et al. A critical role for the membrane-type 1 matrix metalloproteinase in collage phagocytosis. Mol Biol Cell 2006; 17: 4812-26.

27. Gardner H, Broberg A, Pozzi A, et al. Absence of integrin alphalbetal in the mouse causes loss of feedback regulation of collage synthesis in normal and wounded dermis. J Cell Sci 1999; 112: 263-72.

28. Royce SG, Tang ML. The effects of current therapies on airway remodeling in asthma and new possibilities for treatment and prevention. Curr Mol Pharmacol 2009; 2: 169-81.

29. Devulapalli CS, Lodrup Carlsen KC, Haland G, et al. No evidence that early use of inhaled corticosteroids reduces current asthma at 10 years of age. Respir Med 2007; 101: 1625-32.

30. Rhee CK, Kim JW, Park CK, et al. Effect of imatinib on airway smooth muscle thickening in a murine model of chronic asthma. Int Arch Allergy Immunol 2011; 155: 243-51.

31. Asman M, Solarz K, Szilman E, Szilman P. Analysis of expression and amino acid sequence of the allergen Mag 3 in two species of house dust mites-Dermatophagoides farinae and D. pteronyssinus (Acari: Astigmata: Pyroglyphidae). Ann Agric Environ Med 2010; 17: 45-8.

32. Zhang W, Gunst SJ. Interactions of airway smooth muscle cells with their tissue matrix: implications for contraction. Proc Am Thorac Soc 2008; 5: 32-9.

33. Bazan-Socha S, Bukiej A, Marcinkiewicz C, et al. Integrins in pulmonary inflammatory diseases. Curr Pharm Des 2005; 11: 893-901. 